\title{
Analysis of Proteins Copurifying with the CD4/lck Complex Using One-Dimensional Polyacrylamide Gel Electrophoresis and Mass Spectrometry: Comparison with Affinity-Tag Based Protein Detection and Evaluation of Different Solubilization Methods
}

\author{
Oliver K. Bernhard* and Anthony L. Cunningham \\ Center for Virus Research, Westmead Millennium Institute, National Center for HIV Virology Research, \\ Westmead Hospital and the University of Sydney, Westmead, New South Wales, Australia
}

Margaret M. Sheil

Department of Chemistry, University of Wollongong, Wollongong, New South Wales, Australia

\begin{abstract}
Mass spectrometry-based identification of the components of affinity purified protein complexes after polyacrylamide gel electrophoresis (PAGE) and in-gel digest has become very popular for the detection of novel protein interactions. As an alternative, the entire protein complex can be subjected to proteolytic cleavage followed by chromatographic separation of the peptides. Based on our earlier report of a method using affinity tag-mediated purification of cysteine-containing peptides to analyse proteins present in an affinity purification of the $\mathrm{CD} 4 /$ lck receptor complex, we here evaluated the use of one-dimensional polyacrylamide gel electrophoresis for analysis of the same receptor complex purification. Using electrospray and tandem mass spectrometry analyses of tryptic peptides from in-gel digested proteins we identified the components of the CD4 receptor complex along with 23 other proteins that were all likely to be non-specifically binding proteins and mainly different from the proteins detected in our previous study. We compare the alternative strategy with the affinity tag-based method that we described earlier and show that the PAGE-based method enables more proteins to be identified. We also evaluated the use of a more stringent lysis buffer for the CD4 purification to minimise non-specific binding and identified 52 proteins along with CD4 in three independent experiments suggesting that the choice of lysis buffer had no significant effect on the extent of non-specific binding. Non-specific binding was inconsistent and involved various types of proteins underlining the importance of reproducibility and control experiments in proteomic studies. (J Am Soc Mass Spectrom 2004, 15, 558-567) (C) 2004 American Society for Mass Spectrometry
\end{abstract}

$\Lambda$ large number of tools are now available to the proteomics researcher for determining protein identity, relative protein expression or protein interactions in purified protein complexes [1]. In particular mass spectrometry (MS) analysis of the components of purified protein complexes is widely used because identifying new binding partners provides important information on the possible function of any given protein [2]. Using systematic introduction of

Published online February 2, 2004

Address reprint requests to Dr. M. M. Sheil, Department of Chemistry, University of Wollongong, Wollongong, NSW 2522, Australia. E-mail: m.sheil@uow.edu.au

*Also at the Department of Chemistry, University of Wollongong, Wollongong, NSW 2522, Australia. affinity-tagged proteins into cells this strategy can be expanded to provide protein-interaction networks aiding in the understanding of biological problems [3]. When purifying protein complexes for MS analysis, several factors need to be considered. The purification strategy needs to aim at preserving the protein interactions that hold the complex together without introducing non-specific binding of abundant cellular proteins. This can be a problem when the use of detergents is required for solubilizing membrane proteins as it has been suggested that different detergents can influence the protein interactions ultimately detected [4]. Furthermore, cross-linking of protein interactions may be helpful to preserve and identify specific protein interactions [5]. 
After purification of the complex, the protein mixture needs to be digested with trypsin and the tryptic peptides analysed by MS. Because tryptic cleavage of only a few proteins already produces a large number of peptides, the mixture of which is often difficult to analyse, usually at least one more separation step is required prior to MS analysis. This separation can be achieved via SDS polyacrylamide gel electrophoresis (SDS-PAGE) of the protein mixture followed by analysis of the individual slices [5] or by liquid chromatography-MS (LC-MS) analysis of the tryptic peptides derived from all proteins [6]. Using affinity tags introduced at specific amino acid residues and purification of peptides containing the affinity tag is a way to create a representative subset of only few tryptic peptides per original protein thereby increasing the numbers of proteins that can be detected in one MS experiment $[7,8]$.

We have reported previously the use of affinity tag-mediated purification of tryptic peptides containing cysteine residues to identify proteins present in an affinity-purification of CD4 [7], a protein involved in T cell activation [9] and HIV entry [10,11]. We were able to identify the components of the CD4 receptor complex CD4 and lck, a tyrosine kinase that has been reported to associate with CD4 [12] functioning in T cell activation. In addition to those two, we identified several unrelated proteins, which we showed using different control experiments result from non-specific binding. We assumed that non-specific binding was promoted by the use of the non-ionic detergents Triton X-100 and NP-40. Specific protein-protein interactions may have been obscured because of the background from the detergents or ions derived from non-specifically binding proteins. Proteins that did not contain a cysteine residue or where the peptides containing cysteine residues were not detectable with mass spectrometry would also not be identified with that method [7].

In this paper, we report an evaluation of the use of one-dimensional gel electrophoresis followed by mass spectrometry analysis of in-gel digested protein bands as an alternative strategy to identify proteins present in the detergent solubilized sample. We report identification of many different copurifying proteins and provide a comparison between the SDS-PAGE-based method and the previously reported method based on our experience. In order to reduce non-specific binding, we evaluated the use of a detergent combination of NP-40, sodium deoxycholate (DOC) and SDS for cell lysis. This combination was chosen because it has been previously shown that interactions persist in this detergent combination [13] when different subunits of the N-methyl-Daspartate (NMDA) complex could be co-immunoprecipitated. The presence of SDS, which is a potent detergent for disrupting non-covalent protein interactions suggests that weak protein interactions such as non-specific binding will be reduced. We therefore chose to compare the extent of non-specific binding when using this lysis buffer with the non-specific bind- ing we detected when Triton/NP-40 was used for cell lysis.

\section{Experimental}

Unless otherwise specified, all chemicals and reagents were obtained from Sigma (St Louis, MO). PolyT4-5 antibody was a generous gift from Dr Ray Sweet (Smith-Kline Beecham, King of Prussia, PA). Q425 antibody was purified from hybridoma supernatant and conjugated to cyanogen bromide activated sepharose according to the manufacturer's recommendation. Q425 antibody secreting hybridoma cells had been obtained from Dr Quentin Sattentau (Center D'Immunologie de Marseille-Luminy, Marseille, France).

\section{Tissue Culture and Affinity Purification}

The lymphoblastoid cell line CemT4 was obtained from the NIH AIDS Research and Reference Reagent Program (Rockville, MD). Cells were cultivated in RF-10 medium (CSL, Parkville, Victoria, Australia) to a total of $\sim 10^{9}$ cells. Cell lysate preparation and affinity purification was performed similarly as described previously [14]. Briefly, cells were grown to a total amount of $1 \mathrm{x}$ $10^{9}$ cells and lysed in either lysis Buffer 1 or 2 . For lysis in Buffer 1, cells were washed twice with ice cold phosphate-buffered saline (PBS) and lysed in HEPESbuffered saline (HBS), 1\% (vol/vol) Triton X-100, 1\% (vol/vol) NP-40, $10 \mathrm{mM} \mathrm{MgCl}$ and a cocktail of the protease inhibitors phenylmethylsulfonylfluoride, aprotinin and leupeptin at a concentration of $10^{7}$ cells / mL. For lysis in Buffer 2, cells washed twice with ice cold HBS, pH 8.0, $1 \mathrm{mM} \mathrm{MgCl}_{2}, 0.1 \mathrm{mM}$ [ethylenebi$\mathrm{s}$ (oxyethylenetrinitrio)]tetraacetic acid (EGTA) and $0.02 \%$ (wt/vol) $\mathrm{NaN}_{3}$. Cells were then lysed in HBS, $\mathrm{pH}$ 8.0, $1 \mathrm{mM} \mathrm{MgCl}{ }_{2}, 0.1 \mathrm{mM}$ EGTA, $0.02 \%$ (wt/vol) $\mathrm{NaN}_{3}$, $1 \%$ (vol/vol) NP-40, 0.5\% (wt/vol) DOC and $0.1 \%$ (wt/vol) SDS at a concentration of $10^{7}$ cells $/ \mathrm{ml}$. After a $1 \mathrm{~h}$ incubation at $4{ }^{\circ} \mathrm{C}$ insoluble material was pelleted at $10,000 \times g$ and the supernatant was passed through a $0.22 \mu \mathrm{m}$ sterile filter (Millipore, Bedford, MA) and supplemented with $10 \mathrm{mM} \mathrm{CaCl}$. The lysate was then applied to a Q425 affinity column that had been equilibrated with HBS, 1\% (vol/vol) Triton X-100, 1\% (vol/ vol) NP-40 and $10 \mathrm{mM} \mathrm{CaCl}$. A separate column was used for each lysis buffer. The column was washed with $50 \mathrm{~mL}$ tris-buffered saline (TBS), $\mathrm{pH} 8.0,1 \%$ (vol/vol) Triton X-100, 1\% (vol/vol) NP-40 and $10 \mathrm{mM} \mathrm{CaCl} 2$ followed by $20 \mathrm{~mL}$ of TBS, $\mathrm{pH} 8.0,1 \%$ (vol/vol) Triton $\mathrm{X}-100,1 \%$ (vol/vol) NP-40. Proteins were then eluted with TBS, pH 8.0 containing $10 \mathrm{mM}$ ethylenediaminetetraacetic acid (EDTA) and $0.1 \%$ (vol/vol) Triton $\mathrm{X}-100$ and $0.1 \%$ (vol/vol) NP-40. Elution fractions were tested for CD4 using poly T4-5 antibody and Donkey anti rabbit coupled to horseradish peroxidase (HRP) (Amersham-Pharmacia, Uppsala, Sweden). 


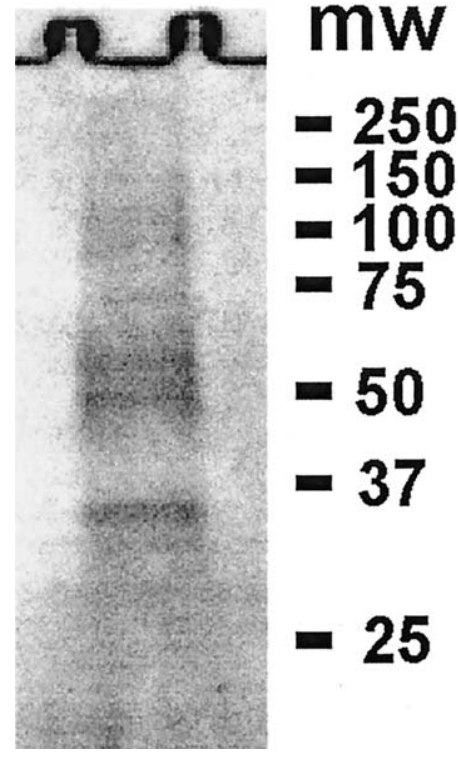

Figure 1. Visualization of proteins present in the affinity-purification of the CD4 receptor complex. CD4 and associating proteins from approximately $10^{9}$ cells were separated on an SDS-Polyacrylamide gel and stained with Coomassie Brilliant Blue.

\section{SDS-PAGE and Coomassie Brilliant Blue Staining}

For SDS-PAGE the two to three elution fractions containing the majority of CD4 were combined and $100 \mu \mathrm{L}$ of Strataclean resin (Stratagene, La Jolla, CA) was added. Proteins were allowed to bind to the resin for $2 \mathrm{~h}$ at $4{ }^{\circ} \mathrm{C}$. The resin was then pelleted and proteins were eluted with $2 \times 30 \mu \mathrm{L}$ sample buffer (62.5 mM Tris, $\mathrm{pH}$ $6.8,0.025 \%$ (wt/vol) bromophenol blue, 10\% (vol/vol) glycerol, $2 \%$ (wt/vol) SDS and $25 \mathrm{mM}$ tris[2-carboxyethyl]phosphine hydrochloride (TCEP) (Pierce, Rockford, IL) at $95{ }^{\circ} \mathrm{C}$. The eluate $(50 \mu \mathrm{L})$ was loaded onto a $8-16 \%$ gradient gel (Gradipore, Frenchs Forest, NSW, Australia) and proteins were separated with a constant current of $25 \mathrm{~mA}$ per gel. Proteins were stained with Coomassie Brilliant Blue as described [14] and destained in $40 \%$ (vol/vol) methanol, 10\% (vol/vol) acetic acid.

\section{In-Gel Digest and Peptide Extraction}

Excised gel-slices were dehydrated with methanol for 5 min and rehydrated with $30 \%$ methanol for $5 \mathrm{~min}$. Slices were washed twice with water and then three times 10 min with $100 \mathrm{mM}$ ammoniumbicarbonate, 30\% (vol/vol) acetonitrile. Gel slices were then crushed into pieces and dehydrated for 5 min with $100 \%$ ethanol. Ethanol was removed and the pieces were dried for $1 \mathrm{~h}$ in vacuum. Depending on the original size of the gel-slice, $50-80 \mu \mathrm{L}$ of trypsin solution $(5 \mathrm{ng} / \mu \mathrm{L}$ sequencing grade modified trypsin (Promega, Madison, WI) in $25 \mathrm{mM}$ ammoniumbicarbonate solution) were added and the protein hydrolysis was carried out at $37^{\circ} \mathrm{C}$ over night. The supernatant was aspirated and proteins were extracted three times by addition of $50 \mu \mathrm{L}$ extraction solution ( $50 \%$ acetonitrile, $5 \%$ formic acid) for $30 \mathrm{~min}$. In between extractions, gel-slices were rehydrated by addition of $30 \mu \mathrm{L}$ water and $20 \mathrm{~min}$ incubation. The aspirated extraction solutions and water supernatants were combined with the aspirated trypsin solution and solvents were evaporated using a SpeedVac centrifuge with moderate heating until $\sim 20 \mu \mathrm{L}$ remained. Water $(20 \mu \mathrm{L})$ was added twice to ensure that the remaining solution was free of acetonitrile. Peptides were purified for MS analysis using ZipTips (Millipore, Bedford, MD) according to the manufacturer's recommendations. Samples were acidified before purification

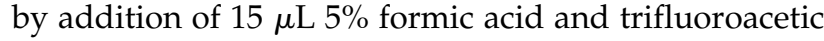
acid was replaced by $5 \%$ formic acid throughout the purification.

\section{Mass Spectrometry Analysis}

Electrospray mass spectrometry (ESI-MS) analyses were carried out as previously described [7] using a Quadrupole-Time-of-flight (Q-TOF) 2 instrument (Micromass, Manchester, UK) in nanoelectrospray mode. Typically 5-8 $\mu \mathrm{L}$ sample were loaded into a coated glass capillary (Protana, Odense, Denmark). The ESI parameters were as follows: Capillary voltage, 900-1200 V; Cone voltage, 30-40 V; desolvation temperature, $40{ }^{\circ} \mathrm{C}$; desolvation gas flow rate, 50-100 1/h. Peptides were detected by acquisition of the $\mathrm{m} / \mathrm{z}$ range from 50-2000 using a $2.4 \mathrm{~s}$ integration time and a $0.1 \mathrm{~s}$ delay. Precursor ions were selected for fragmentation within a mass window of 4 $m / z$. All multiply charged ions that were clearly distinguishable from the background were selected for fragmentation. MS/MS spectra were collected using collision cell voltages from $25 \mathrm{~V}$ to $35 \mathrm{~V}$ with argon as the collision gas. The instrument was calibrated with a solution of $100 \mathrm{fM}$ [Glu ${ }^{1}$-Fibrinopeptide B in $40 \%$ acetonitrile, $2.5 \%$ formic acid. To reduce the intensity of detergent-derived singly charged species, the multichannel plate (MCP) detector voltage on the detector was reduced to $2000 \mathrm{~V}$ during MS acquisitions whilst kept at $2300 \mathrm{~V}$ during MS/MS acquisitions [15].

\section{Protein Identification}

Spectra were interpreted and matched using either the MASCOT search engine (http://www.matrixscience. com/cgi/index.pl?page=/search_form_select.html) or by manual de-novo sequencing. Manual sequencing was also used to confirm all peptide matches obtained via MASCOT and performed similarly as described before [7]: Amino acid sequence tags obtained from the MS/MS spectra were used for database searches with the PepSea software (Protana, Odense, Denmark, http://195.41.108.38/PepSeaIntro.html) or the ScanProsite software (SWISS-PROT database, Swiss Institute of Bioinformatics (SIB), Geneva, Switzerland, http:/ / au.expasy.org/tools/scanprosite/). Proteins containing the sequence tag were subjected to a theoretical digest with trypsin and the resulting peptides searched for the 
Table 1. Proteins identified by ESI-MS/MS in all experiments

\begin{tabular}{|c|c|c|c|c|c|c|c|c|c|}
\hline \multirow[b]{2}{*}{ Protein name } & \multirow[b]{2}{*}{ Sprot \# $\#^{a}$} & \multirow{2}{*}{$\begin{array}{l}\mathrm{MW} \\
\mathrm{kDa}\end{array}$} & \multirow{2}{*}{$\begin{array}{r}\text { Number } \\
\text { of Cys }\end{array}$} & \multicolumn{6}{|c|}{ Peptides identified in experiment } \\
\hline & & & & {$[7]^{\mathrm{b}}$} & $1 A^{c}$ & $1 \mathrm{~B}$ & $2 \mathrm{~A}$ & 2B & 20 \\
\hline Leucine-rich protein & P42704 & 145 & 21 & · & . & · & 8 & · & \\
\hline Eukaryotic translation initiation factor 3 subunit 8 & Q99613 & 105 & 12 & · & · & 2 & · & · & $\cdot$ \\
\hline Importin $\beta$-2 subunit & Q92973 & 101 & 26 & . & . & . & 1 & • & \\
\hline Importin beta-1 subunit & Q14974 & 97 & 23 & . & . & . & 3 & • & \\
\hline Eukaryotic translation initiation factor 3 subunit 9 & P55884 & 92 & 7 & · & · & 1 & $\cdot$ & · & \\
\hline Heat-shock protein HSP 90-alpha & P07900 & 85 & 7 & · & . & $\cdot$ & 3 & . & \\
\hline Neprilysin & P08473 & 85 & 12 & . & . & . & . & 1 & \\
\hline Heat-shock protein HSP 90-beta & P08238 & 83 & 6 & · & · & $\cdot$ & 8 & · & \\
\hline Structure-specific recognition protein 1 & Q08945 & 81 & 6 & · & 2 & 4 & $\cdot$ & · & . \\
\hline Annexin A6 & P08133 & 76 & 6 & · & · & $\cdot$ & $\cdot$ & 9 & 11 \\
\hline Nucleolin & P19338 & 76 & 1 & · & · & 5 & $\cdot$ & · & 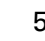 \\
\hline DEAD-box protein 3 & 000571 & 73 & 7 & . & . & 1 & . & . & \\
\hline Heat shock cognate $71 \mathrm{kDa}$ protein & P11142 & 71 & 4 & · & 4 & 2 & 3 & • & \\
\hline Probable RNA-dependent helicase p68 & P17844 & 69 & 9 & . & . & 2 & . & . & \\
\hline Phenylalanyl-tRNA synthetase beta chain & Q9NSD9 & 66 & 11 & · & $\cdot$ & 1 & $\cdot$ & · & \\
\hline Eukaryotic translation initiation factor 3 subunit 7 & 015371 & 64 & 11 & · & · & 4 & $\cdot$ & · & \\
\hline $60 \mathrm{kDa}$ Heat shock protein & P10809 & 58 & 3 & . & . & $\cdot$ & 4 & . & \\
\hline P56lck & P06239 & 58 & 9 & 1 & 2 & 2 & 9 & 16 & $2^{\mathrm{c}}$ \\
\hline ATP synthase alpha chain, mitochondrial & P25705 & 55 & 2 & . & . & $\cdot$ & 3 & . & \\
\hline $\mathrm{CD} 4$ & P01730 & 55 & 11 & 2 & 3 & 1 & 3 & 7 & $5^{c}$ \\
\hline Vimentin & P08670 & 54 & 1 & . & . & $\cdot$ & 1 & . & \\
\hline Eukaryotic translation initiation factor 3 subunit 6 & Q64252 & 52 & 7 & · & 2 & 6 & . & . & \\
\hline Tubulin alpha- 1 chain & P05209 & 50 & 12 & . & . & 1 & · & . & \\
\hline Tubulin beta- 1 chain & P07437 & 50 & 9 & · & $2^{\mathrm{e}}$ & 1 & $\cdot$ & · & \\
\hline Heterogeneous nuclear ribonucleoprotein $\mathrm{H}$ & P31943 & 49 & 5 & · & · & 1 & $\cdot$ & · & \\
\hline$\alpha$ enolase & P06733 & 47 & 6 & · & · & $\cdot$ & 8 & • & \\
\hline Eukaryotic initiation factor $4 \mathrm{~A}-\mathrm{II}$ & Q14240 & 46 & 4 & · & $\cdot$ & · & 1 & · & \\
\hline GA17 protein & 060735 & 43 & 8 & · & 1 & $\cdot$ & $\cdot$ & • & \\
\hline Actin, cytoplasmic I & P02570 & 42 & 6 & · & · & $\cdot$ & 2 & • & \\
\hline Guanine nucleotide-binding protein $\mathrm{G}(\mathrm{i}), \alpha-2$ subunit & P04899 & 40 & 10 & · & · & $\cdot$ & $\cdot$ & · & se \\
\hline Annexin A1 & P04083 & 39 & 4 & . & . & $\cdot$ & $\cdot$ & 2 & 2 \\
\hline Heterogeneous nuclear ribonucleoprotein $\mathrm{A} 1$ & P09651 & 39 & 2 & . & . & 1 & 1 & . & \\
\hline Annexin A2 & P07355 & 38 & 4 & · & $\cdot$ & $\cdot$ & $\cdot$ & 8 & 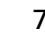 \\
\hline Heterogeneous nuclear Ribonucleoprotein D0 & Q14103 & 38 & 3 & · & · & 1 & $\cdot$ & · & \\
\hline Voltage-dependent anion-selective channel protein 2 & P45880 & 38 & 10 & · & $\cdot$ & $\cdot$ & 1 & • & \\
\hline Heterogeneous nuclear ribonucleoproteins A2/B1 & P22626 & 37 & 1 & · & $\cdot$ & 1 & $\cdot$ & · & \\
\hline Eukaryotic translation initiation factor 3 subunit 2 & Q13347 & 37 & 7 & 1 & 1 & $\cdot$ & $\cdot$ & · & \\
\hline Glyceraldehyde 3-phosphate dehydrogenase & P04406 & 36 & 3 & . & . & . & 6 & 2 & \\
\hline Nuclease sensitive element binding protein 1 & P16991 & 36 & 0 & · & . & $\cdot$ & $\cdot$ & . & 2 \\
\hline Guanine nucleotide binding protein & P25388 & 35 & 8 & 3 & $\cdot$ & . & $\cdot$ & . & \\
\hline $60 \mathrm{~S}$ acidic ribosomal protein $\mathrm{P} 0$ & P05388 & 34 & 3 & · & · & 2 & $\cdot$ & · & 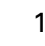 \\
\hline $40 \mathrm{~S}$ ribosomal protein SA & P08865 & 33 & 2 & . & . & 4 & $\cdot$ & . & \\
\hline Nucleophosmin & P06748 & 33 & 3 & . & . & 1 & . & . & \\
\hline Voltage-dependent anion-selective channel protein 1 & P21796 & 31 & 2 & · & · & $\cdot$ & 1 & • & \\
\hline $40 \mathrm{~S}$ ribosomal protein $\mathrm{S} 3 \mathrm{~A}$ & P49241 & 30 & 4 & $\cdot$ & $\cdot$ & 1 & 1 & · & \\
\hline $60 \mathrm{~S}$ ribosomal protein $\mathrm{L7A}$ & P11518 & 30 & 3 & · & · & $\cdot$ & $\cdot$ & · & ( \\
\hline Voltage-dependent anion-selective channel protein 3 & Q9Y277 & 30 & 6 & · & $\cdot$ & $\cdot$ & 1 & • & \\
\hline Prohibitin & P35232 & 30 & 1 & · & $\cdot$ & · & 2 & · & \\
\hline $40 \mathrm{~S}$ ribosomal protein $\mathrm{S} 4$ & P12750 & 29 & 4 & · & · & $\cdot$ & $\cdot$ & • & 1 \\
\hline $60 \mathrm{~S}$ ribosomal protein $\mathrm{L7}$ & P18124 & 29 & 1 & · & $\cdot$ & · & $\cdot$ & · & 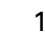 \\
\hline Dehydrogenase/reductase SDR family member 2 & Q13268 & 27 & 6 & · & $\cdot$ & $\cdot$ & 2 & . & \\
\hline Elongation factor 1-beta & P24534 & 25 & 3 & · & $\cdot$ & $\cdot$ & 2 & • & \\
\hline HSPC029 & Q9Y6D1 & 25 & 5 & 2 & . & . & . & . & \\
\hline $40 \mathrm{~S}$ ribosomal protein S8 & P09058 & 24 & 5 & · & · & $\cdot$ & $\cdot$ & · & ( \\
\hline GTP-binding nuclear protein RAN & P17080 & 24 & 3 & $\cdot$ & $\cdot$ & $\cdot$ & 1 & 1 & \\
\hline $40 \mathrm{~S}$ ribosomal protein $\mathrm{S} 7$ & P23821 & 22 & 0 & $\cdot$ & $\cdot$ & $\cdot$ & $\cdot$ & $\cdot$ & 1 \\
\hline $40 \mathrm{~S}$ ribosomal protein S9 & P46781 & 22 & 1 & · & $\cdot$ & $\cdot$ & $\cdot$ & - & 1 \\
\hline $60 \mathrm{~S}$ ribosomal protein L18 & Q07020 & 22 & 2 & · & $\cdot$ & $\cdot$ & $\cdot$ & · & 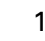 \\
\hline $60 \mathrm{~S}$ ribosomal protein $\mathrm{L} 11$ & P39026 & 20 & 4 & . & . & . & . & . & 1 \\
\hline Myosin regulatory light chain & P19105 & 20 & 1 & 1 & $\cdot$ & $\cdot$ & $\cdot$ & · & \\
\hline $40 \mathrm{~S}$ ribosomal protein $\mathrm{S} 10$ & P46783 & 19 & 0 & . & $\cdot$ & . & $\cdot$ & . & 1 \\
\hline $40 \mathrm{~S}$ ribosomal protein S18 & P25232 & 18 & 0 & . & $\cdot$ & . & . & $\dot{C}$ & \\
\hline
\end{tabular}


Table 1. (Continued)

\begin{tabular}{|c|c|c|c|c|c|c|c|c|c|}
\hline \multirow[b]{2}{*}{ Protein name } & \multirow[b]{2}{*}{ Sprot \# $\#^{a}$} & \multirow{2}{*}{$\begin{array}{l}\mathrm{MW} \\
\mathrm{kDa}\end{array}$} & \multirow{2}{*}{$\begin{array}{r}\text { Number } \\
\text { of Cys }\end{array}$} & \multicolumn{6}{|c|}{ Peptides identified in experiment } \\
\hline & & & & {$[7]^{\mathrm{b}}$} & $1 A^{c}$ & 1B & $2 \mathrm{~A}$ & $2 \mathrm{~B}$ & $2 \mathrm{C}$ \\
\hline $40 \mathrm{~S}$ ribosomal protein $\mathrm{S} 13$ & Q02546 & 17 & 0 & . & . & . & . & $\cdot$ & 1 \\
\hline Myosin essential light chain & P16475 & 17 & 3 & 1 & $\cdot$ & $\cdot$ & $\cdot$ & $\cdot$ & \\
\hline 40 S ribosomal protein S19 & P39019 & 16 & 0 & $\cdot$ & $\cdot$ & $\cdot$ & $\cdot$ & $\cdot$ & 1 \\
\hline 40 S ribosomal protein S24 & P16632 & 15 & 0 & $\cdot$ & $\cdot$ & $\cdot$ & $\cdot$ & $\cdot$ & 1 \\
\hline $60 \mathrm{~S}$ ribosomal protein L22 & P35268 & 15 & 1 & $\cdot$ & $\cdot$ & $\cdot$ & $\cdot$ & $\cdot$ & 1 \\
\hline $40 \mathrm{~S}$ ribosomal protein $\mathrm{S} 12$ & P25398 & 14 & 6 & 1 & · & · & $\cdot$ & $\cdot$ & \\
\hline Histone 2B & $\mathrm{P} 02278^{f}$ & 14 & 0 & . & . & . & . & . & 2 \\
\hline 60 S Acidic Ribosomal Protein P1 & P05386 & 12 & 2 & 2 & $\cdot$ & $\cdot$ & $\cdot$ & $\cdot$ & \\
\hline Ubiquitin & P02248 & 8.5 & 0 & $\cdot$ & $\cdot$ & $\cdot$ & $\cdot$ & $\cdot$ & 1 \\
\hline Total: 66 proteins & & & & & 8 & 23 & 26 & 8 & 26 \\
\hline
\end{tabular}

aswiss-Prot accession number

bDetected in our previous study[7]

${ }^{c}+$ Indicates in which of five experiments the protein was detected. Experiment labels $1 / 2$ refer to the respective lysis buffer Triton X-100/NP-40 or NP-40/DOC/SDS and A/B/C refer to one of two or three independent experiments.

${ }^{\mathrm{d}}$ Several ions typical of CD4- or Ick-derived peptides were detected but not subjected to fragmentation.

ethe detected peptide matched two or more tubulin beta chains

${ }^{f}$ the detected peptide matched various alleles of the same protein, one allele is listed representative for all matches.

peptide that contained the sequence tag. To be identified as the sequence of a fragmented ion, the peptide mass needed to be equivalent to the experimentally obtained mass including modifications such as oxidized methionine residues or carboxyamidomethylcysteine residues. Additionally, a series of product ions from the MS/MS spectrum had to match the predicted $y$ and $b$ ions of the sequence requiring a mass accuracy of $0.1 \%$ for both the masses of product ions and the mass differences between product ions representing amino acids. The full peptide sequence was again entered into the ScanProsite search engine and the protein was considered to be identified conclusively in the affinity chromatography-derived sample if it was the only human protein producing this peptide after a tryptic digest.

\section{Results}

\section{Proteins Detected Visually in the Coomassie Stained Gels}

To identify proteins purifying together with CD4, the affinity-purified complexes from $\sim 1 \times 10^{9}$ cells were concentrated and separated on an $8-16 \%$ gradient polyacrylamide gel. Figure 1 shows a representative example for all experiments of a Coomassie stained gel containing the proteins of a CD4 affinity purification using the SDS containing lysis buffer. The visible pattern is very weak and apart from major bands at 60, 50, and $37 \mathrm{kDa}$, several minor bands of different strengths (but all very weak) can be seen.

\section{Proteins Identified in the Sample Prepared with Triton X-100/NP-40 Lysis Buffer}

Two experiments were carried out to determine proteins present in an affinity purification of CD4 employing the Triton X-100/NP-40 based lysis buffer. Whereas in the first experiment, only visible protein bands were excised and analysed, in the second series of experiments, the entire lane of the gel was dissected into slices from the very top of the gel down to the area representing the molecular weight of $15 \mathrm{kDa}$. A total of 23 proteins were identified in the two different experiments using the 1D-PAGE-MS strategy. Table 1 lists all identified proteins. In all, 8 proteins were identified in the first experiment, 6 of them were identified again in the second experiment along with 15 other proteins.

\section{Proteins Identified in the Sample Prepared with NP-40/DOC/SDS Lysis Buffer}

To investigate whether the use of a more stringent detergent combination has a positive effect on reducing non-specific binding, three experiments were carried out employing a different detergent combination including SDS in the lysis buffer. CD4 complexes were purified as described above and the presence of CD4 in lysate and elution fractions but not in the flow-through fraction of the affinity column was confirmed (data not shown) to ensure that CD4 binding to the antibody is not abrogated in the presence of SDS. Figure 2 shows a representative mass spectrometry analysis of the purified peptide mixture obtained from a tryptic digest of an excised band containing only a barely visible amount of protein. The inset shows the expansion of a part of the spectrum allowing the identification of doubly charged ions at $m / z 802.6$ and 803.6. Figure 3 shows a MS/MS spectrum of the ion at $m / z 802.6$ leading to the unambiguous identification of elongation factor $1-\beta$. Sixteen peptide ions were identified in this gel slice as indicated with the labels resulting in the identification of 9 different proteins (excluding trypsin). A total of 54 proteins were identified in three independent experiments using 1D-PAGE MS analysis of purified CD4 derived from cells lysed with NP-40/DOC/SDS buffer. 
Table 1 lists all proteins that were identified in these experiments.

\section{Discussion}

Proteins usually carry out their function in complexes and the knowledge of the interacting partners is crucial to determine the function of a given protein. CD4 has multiple functions in $\mathrm{T}$ cell activation [9], as an interleukin-16 receptor [16] and in HIV-1 entry [10, 11]. We have investigated previously proteins copurifying with CD4 in search for novel binding partners that could play a role in the function of this receptor [7]. In that study proteins were identified using affinity tag-mediated purification of tryptic peptides carrying a biotin tag at cysteine residues. However, we were only able to identify the CD4/lck complex along with several nonspecifically binding proteins. We suggested that proteins present in the affinity chromatography-derived sample could have escaped detection because they did not contain a cysteine residue required for biotin labeling or the labeled peptide was not detectable via ESI-MS analysis [7]. To investigate the possibility that potential protein partners were missed, in this study we evaluated the use of SDS-PAGE followed by in-gel digest and mass spectrometry analysis as an alternative method to the affinity tag-mediated purification of biotin labeled peptides reported in our previous study [7]. SDS-PAGE has the advantage that the protein pattern can be visualised with staining and that individual bands can be excised and the approximate molecular weight assists in their later identification. As Figure 1 shows, in all our experiments, only a very faint pattern of proteins was visible after the gel was stained showing that affinity purification of CD4 from lymphoid cells produces only a small amount of protein, roughly estimated less than $1 \mu \mathrm{g}$ from the intensity of the band. Still, the employed strategy led to the identification of many CD4-derived peptides for which clean and easy-to-interpret MS/MS spectra were obtained. The same applies to the tyrosine kinase lck. Most of the CD4 is associated with lck in lymphoid cells [12], so the purification strategy led to the isolation of a similar amount of lck so that this protein was identified as easily as CD4.

Besides a band at $\sim 55 \mathrm{kDa}$, that could incorporate either or both CD4 (55 kDa) and lck (58 kDa), several other albeit often barely visible bands were present in the protein pattern. Analysis of gel slices containing those proteins was still able to unambiguously identify the proteins that were contained in the slices. Even regions of the gel that did not contain any visible protein band yielded protein data upon mass spectrometry analysis demonstrating the ability of the strategy to detect proteins in sub Coomassie stainable amounts (i.e., <pmols). In some instances, up to nine different proteins along with trypsin could be identified in one mass spectrometry analysis of a single gel slice that contained only a barely detectable amount of protein (Figures 2 and 3, Table 2).

A total of 23 different proteins were identified in two different experiments in the affinity purification of CD4 employing similar purification methods as in our previous report [7]. However, in that study, we were only able to detect a total of 10 proteins in three different experiments indicating that the SDS-PAGE based method is a more powerful approach towards identifying most of the proteins present. CD4 and lck were detected in all performed experiments, but only two other proteins were identified by both technological approaches. Significant run-to-run differences in the intensity of non-specific binding to CD4 probably account for much of these differences but the differential abilities of the two methods to identify proteins is also a factor. Whereas the SDS-PAGE based method can identify a protein based on any of its tryptic peptides, the affinity tag-based method specifically detects only peptides containing a cysteine. As not all proteins contain a cysteine residue and not all peptides containing a cysteine residue can be observed in a mass spectrometry experiment [7], the SDS-PAGE based method has the potential to identify more of the proteins present in the sample. Of the 66 proteins we identified in this study, 9 do not contain a cysteine residue and therefore would have been missed using the affinity tag-mediated purification. In contrast, non-PAGE based methods have the advantage of identifying proteins which migrate poorly in gels [17] and the detection of the small acidic myosin and ribosomal proteins in the affinity tag-based method could be because this method does not involve such a separation. Therefore the observed difference in the identified proteins is likely to be a combination of both the differential protein binding in different experiments, the different sensitivities of the methods but also the lower overall sensitivity of the affinity tag-based method because of the interference by the detergents.

When choosing the appropriate method for an investigation, several other factors must be taken into account concerning the speed with which the experiments and the protein identification can be carried out. Protein identification fundamentally relies on how efficiently tandem mass spectra can be matched to tryptic peptides of proteins. Whereas the affinity tag-based method led to detection of mainly peptides of high molecular weight [7], which were often difficult to match, the gel-based method mainly detected peptides in the mass range of 1000 to $2000 \mathrm{Da}$ which is more convenient for manual analysis. Also the samples were less contaminated with singly charged species as the SDS-PAGE separation eliminated the non-ionic detergents that caused a significant background in the affinity tag-based method [7]. The time for sample preparation is another factor. The affinity tag-based method has the advantage that representative peptides obtained from all proteins are 


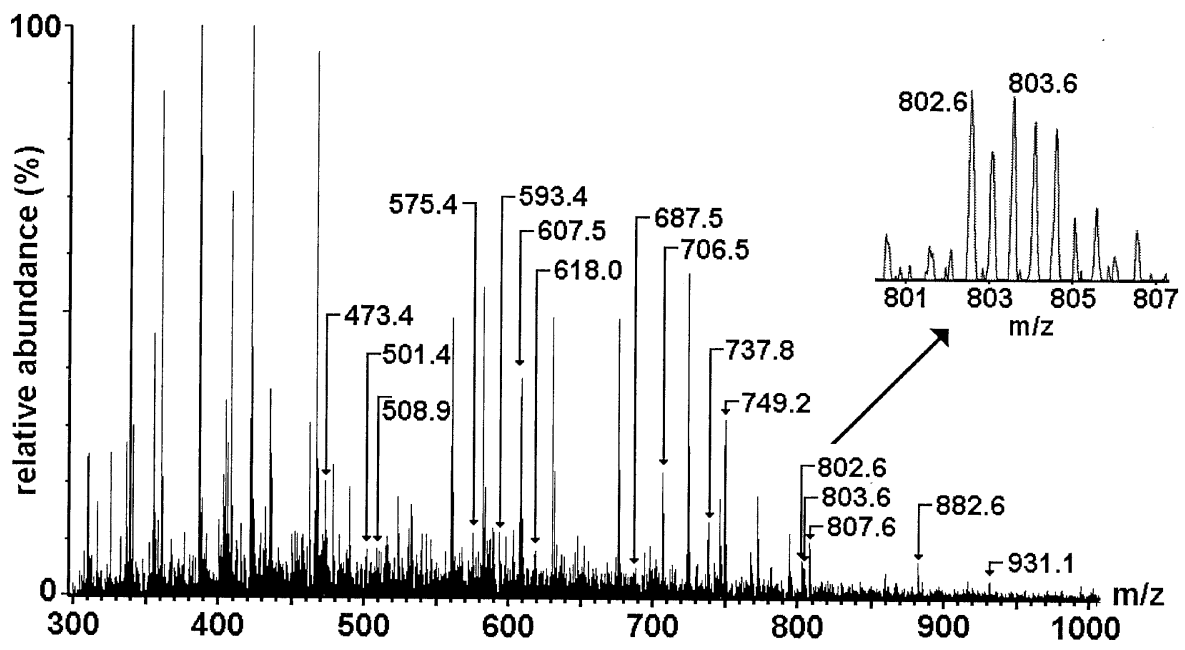

Figure 2. Mass spectrometry identification of peptides derived from the tryptic digest of an excised gel slice. The ESI-mass spectrum of the tryptic peptides derived from the proteins in a gel slice of about $30 \mathrm{kDa}$ is shown together with the ions at $m / z 802.6$ and 803.6 enlarged.

present in a single fraction, which is relatively easy to investigate. Moreover the SDS-PAGE based method leads to a high degree of redundant protein identification. More than 15 peptides have been observed for lck for example (Table 1). Also each gel slice needs to be analysed separately leading to a much more time-consuming analysis when using this method. Nevertheless the investigation of slices, provides the analyst with the approximate molecular weight of the protein (as noted above), which can be an advantage when doing a database search for protein identification. Clearly this study demonstrates that no one method is capable of identifying all proteins present in such a complex mixture. Each method has its particular advantages, however for our aims the
SDS-PAGE based method seemed more efficient because more proteins were detected and the spectra obtained were generally cleaner. When choosing the appropriate method for an investigation, those factors need to be taken into account and to achieve detection of as many proteins as possible, the use of both strategies may be necessary.

Because of the high degree of non-specific binding to CD4 detected in our earlier study, we aimed to evaluate a different purification strategy that reduces the non-specific binding to CD4. Also, a part of CD4 has been reported to participate in detergent-insoluble microdomains [18] and this compartment together with any possible associating molecules, is likely to escape detection in a method employing cell lysis in

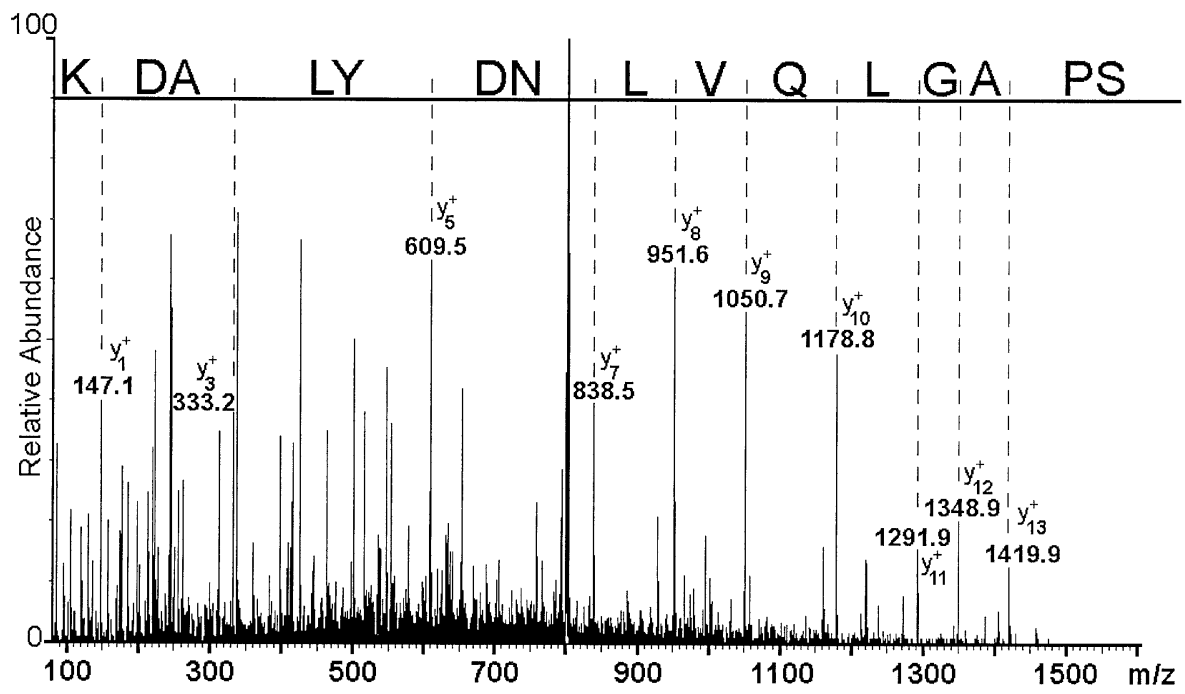

Figure 3. Identification of proteins via tandem mass spectrometry. The MS/MS spectrum of the ion at $m / z$ 802.6 (2+, precursor mass $1604.2 \mathrm{Da})$ is shown. Singly charged product ions are labeled. The peptide sequence SPAGLQVLNDYLADK identified it as derived from the elongation factor 1- $\beta$. 
Table 2. Peptides and proteins identified in an excised gel-slice of $\sim 30 \mathrm{kDa}$

\begin{tabular}{|c|c|c|c|c|c|c|}
\hline $\begin{array}{l}\text { Precursor } \\
m / z^{\mathrm{a}}\end{array}$ & $\begin{array}{l}\text { Peptide } \\
\text { mass }^{b}\end{array}$ & Sequence $^{c}$ & $\begin{array}{c}\text { MASCOT } \\
\text { Score }\end{array}$ & Protein Name & $\begin{array}{l}\text { Swiss } \\
\text { Prot\# }\end{array}$ & $\begin{array}{l}\mathrm{MW} \\
\mathrm{kDa}\end{array}$ \\
\hline 473.4 & 944.6 & LVPVGYGIK & 12 & Elongation factor $1-\beta$ & P24534 & 24.6 \\
\hline 501.4 & 1001.5 & LITEDVQGK & 25 & $40 \mathrm{~S}$ ribosomal protein S3A & P49241 & 29.8 \\
\hline 508.9 & 1015.6 & LTLSALVDGK & 34 & Voltage-dependent anion-selective channel protein 2 & P45880 & 38.1 \\
\hline 575.4 & 1029.6 & LTLSALIDGK & 33 & Voltage-dependent anion-selective channel protein 3 & Q9Y277 & 30.7 \\
\hline 593.4 & 1184.7 & DLQNVNITLR & 26 & Prohibition & P35232 & 29.8 \\
\hline 607.5 & 1212.7 & VLPSITTEILK & 34 & Prohibition & P35232 & 29.8 \\
\hline 618.0 & 1233.7 & IEVIEIM*TDR & 29 & Heterogeneous nuclear ribonucleoprotein A1 & P09651 & 38.7 \\
\hline 687.5 & 1373.7 & WTEYGLTFTEK & 7 & Voltage-dependent anion-selective channel protein 1 & P21796 & 30.6 \\
\hline 706.5 & 1410.8 & GALQNIIPASTGAAK & 32 & Glyceraldehyde 3-phosphate dehydrogenase & P04406 & 35.9 \\
\hline 737.8 & 2210.1 & LGEHNIDVLEGNEQFINAAK & 47 & Trypsin & P00761 & 23.5 \\
\hline 749.2 & 2244.1 & VIISAPSADAPM*FVM*GVNHEK & 13 & Glyceraldehyde 3-phosphate dehydrogenase & P04406 & 35.9 \\
\hline 802,6 & 1602.8 & SPAGLQVLNDYLADK & 57 & Elongation factor $1-\beta$ & P24534 & 24.6 \\
\hline 803.6 & 1604.9 & VAVVTGSTSGIGFAIAR & 17 & Dehydrogenase/reductase SDR family member 2 & Q13268 & 27.3 \\
\hline 807.6 & 1612.9 & LVINGNPITIFQER & 46 & Glyceraldehyde 3-phosphate dehydrogenase & P04406 & 35.9 \\
\hline 882.6 & 1762.8 & LISWYDNEFGYSNR & 42 & Glyceraldehyde 3-phosphate dehydrogenase & P04406 & 35.9 \\
\hline 931.1 & 1860.0 & SPALLLSQLLPYM*ENR & 45 & Dehydrogenase/reductase SDR family member 2 & Q13268 & 27.3 \\
\hline
\end{tabular}

${ }^{a}$ Given is the experimentally determined $\mathrm{m} / \mathrm{z}$ value.

${ }^{b}$ Given is the theoretical uncharged monoisotopic peptide mass.

${ }^{\mathrm{c}} \mathrm{M}{ }^{*}$ indicates oxidized methionine.

cold Triton X-100. To reduce contamination with abundant proteins from the transcription/translation machinery and to generally increase solubility of membrane proteins a detergent combination was used for cell lysis that had been reported to efficiently solubilize proteins from the NMDA receptor complex [19]. Co-immunoprecipitation studies on the NMDA receptor complex have demonstrated that interactions between different subunits of the complex persist even in the presence of up to $0.2 \%$ SDS $[13,20]$. However, SDS is a potent detergent for inhibiting noncovalent protein-protein interactions and its incorporation should reduce non-specific protein interactions. Table 1 lists all proteins identified in three independent experiments, in which a total of 49 proteins were identified together with CD4 and lck. Only these two were identified in all experiments. Otherwise the pattern of copurifying proteins is different between the individual experiments and also different from the experiments employing the Triton X-100/NP-40 lysis buffer. However, there was no obvious reduction in non-specific binding and any conclusions on the nature of binding proteins in relation to the employed lysis buffer cannot be drawn because of the variability between the experiments. Based on these data, it cannot be stated whether employing the NP-40/DOC/SDS lysis buffer has any beneficial influence on non-specific protein binding. It could very well be that it does decrease nonspecific binding but also induces partial unfolding of CD4 and/or lck-domains that are then accessible to non-specific binding, counteracting such benefits derived. Thus the choice of lysis buffer in this experiment has no significant influence on purification of both the CD4 receptor complex and on non-specific binding.
Whereas our strategy aimed to reduce non-specific binding by using SDS as a detergent for cell lysis, tandem affinity purification (TAP) would be an alternative way of reducing the presence of non-specifically binding proteins when purifying complexes for mass spectrometry analysis. It is normally performed by recombinantly expressing the protein of interest containing two different affinity tags with which two different affinity purifications are performed. The sequential purification leads to a high purity of the complex increasing the chance that detected proteins are specific interactors. It has been successfully used for several proteomic studies including for example the human Smad proteins [21]. Those strategies are especially efficient when complexes are purified that contain large numbers of subunits that provide a big platform for non-specific binding. In our study it could have been performed using two different monoclonal antibodies for affinity-purification of CD4, even using two columns with the same antibody would have been an option. Alternatively, CD4 could have been expressed as a recombinant tagged protein such as (His) 6 -tagged in a CD4-negative cell line like A2.01 and TAP carried out via Ni-NTA and Q425 affinity chromatography. However, some preliminary studies have shown difficulties when eluting CD4 off columns made of other immobilised CD4 antibodies such as OKT4 (data not shown). Recombinantly expressing tagged CD4 is also rather laborious so we have considered tandem-affinity purification to be a method of choice if the results obtained in this study had shown evidence that a large complex were present. As no evidence of a large CD4-containing complex could be found, we did not evaluate this option further.

Eight proteins were found to copurify with CD4 in 
our previous report [7] but none of them was functionally related to CD4 and using control experiments, we could show that all of them are non-specifically binding proteins. In this study, we detected a further 62 proteins. As none of the detected proteins showed consistent signals in all experiments as observed for p56lck, the detected proteins were unlikely to be functionally related to CD4, similarly to the proteins detected in our previous study [7]. Therefore no experiments were conducted to test the specificity of the interaction. This could have been done using independent technologies or by conducting control experiments with non-specifically absorbing beads as we [7] and others [2] have shown. Along with the vast majority of the detected proteins, which are derived from the abundant protein synthesis, transcription or RNA processing machinery, several proteins from the cytoskeleton (actin, tubulin, and vimentin) were detected. As we have previously stated, a connection between CD4 and the cytoskeleton has been reported and the detection of components of the cytoskeleton could be a result thereof [22, 23]. However, more investigation is required to further clarify the mechanism of an association between CD4 and the cytoskeleton.

In conclusion, this study shows that neither of the above-investigated strategies is superior in detecting the proteins present in the affinity-chromatography-derived sample. Given the large number of non-specifically binding proteins and the different protein families they belong to it also shows the importance of reproducibility and control experiments to validate protein interactions detected in such settings. Finally it suggests that this strategy will not identify further CD4-binding proteins in the resting $\mathrm{T}$ lymphoid cells that were investigated here, as those interactions are probably of weak and/or transient nature.

\section{Acknowledgments}

OKB was supported by a Chemfonds-Stipendium" which is partially supported by the Bundesministerium für Bildung und Wissenschaft of Germany. OKB is now being supported by an International Postgraduate Research Scholarship of the University of Sydney. The authors thank the Cecilia Kilkeary Foundation for their donation that enabled the purchase of a license for the MassLynx software at the Westmead Millennium Institute. They also gratefully acknowledge grants from the Australian Research Council and the University of Wollongong, enabling the purchase of the Q-TOF Mass Spectrometer.

\section{References}

1. Patterson, S. D.; Aebersold, R. H. Proteomics: The First Decade and Beyond. Nat. Gen. Suppl. 2003, 33, 311-323.

2. Ranish, J. A.; Yi, E. C.; Leslie, D. M.; Purvine, S. O.; Goodlet, D. R.; Eng, J.; Aebersold, R. The Study of Macromolecular Complexes by Quantitative Proteomics. Nat. Gen. 2003, 33, 349-355.

3. Ho, Y.; Gruhler, A.; Heilbut, A.; Bader, G. D.; Moore, L.; Adams, S. L.; Millar, A.; Taylor, P.; Bennett, K.; Boutilier, K.;
Yang, L.; Wolting, C.; Donaldson, I.; Schandorff, S.; Shewnarane, J.; Vo, M.; Taggart, J.; Goudreault, M.; Muskat, B.; Alfarano, C.; Dewar, D.; Lin, Z.; Michalickova, K.; Willems, A. R.; Sassi, H.; Nielsen, P. A.; Rasmussen, K. J.; Andersen, J. R.; Johansen, L. E.; Hansen, L. H.; Jespersen, H.; Podtelejnikov, A.; Nielsen, E.; Crawford, J.; Poulsen, V.; Sorensen, B. D.; Matthiesen, J.; Hendrickson, R. C.; Gleeson, F.; Pawson, T.; Moran, M. F.; Durocher, D.; Mann, M.; Hogue, C. W.; Figeys, D.; Tyers, M. Systematic Identification of Protein Complexes in Saccharomyces cerevisiae. Nature 2002, 415, 180-183.

4. Beyers, A. D.; Spruyt, L. L.; Williams, A. F. Molecular Associations Between the T-lymphocyte Antigen Receptor Complex and the Surface Antigens CD2, CD4, or CD8, and CD5. Proc. Natl. Acad. Sci. U.S.A. 1992, 89, 2945-2949.

5. Wine, R. N.; Dial, J. M.; Tomer, K. B.; Borchers, C. H. Identifications of Components of Protein Complexes Using a Fluorescent Photo-Cross-Linker and Mass Spectrometry. Anal. Chem. 2002, 74, 1939-1945.

6. Link, A. J.; Eng, J.; Schieltz, D. M.; Carmack, E.; Mize, G. J.; Morris, D. R.; Garvik, B. M.; Yates, J. R., III. Direct Analysis of Protein Complexes Using Mass Spectrometry. Nat. Biotechnol. 1999, 17, 676-682.

7. Bernhard, O. K.; Burgess, J. A.; Hochgrebe, T.; Sheil, M. M.; Cunningham, A. L. Mass Spectrometry Analysis of CD4 Associated Proteins Using Affinity Chromatography and Affinity Tag-Mediated Purification of Tryptic Peptides. Proteomics 2003, 3, 139-146.

8. Spahr, C. S.; Susin, S. A.; Bures, E. J.; Robinson, J. H.; Davis, M. T.; McGinley, M. D.; Kroemer, G.; Patterson, S. D. Simplification of Complex Peptide Mixtures for Proteomic Analysis: Reversible Biotinylation of Cysteinyl Peptides. Electrophoresis 2000, 21, 1635-1650.

9. Gay, D.; Maddon, P.; Sekaly, R.; Tale, M. A.; Godfrey, M.; Long, E.; Goldstein, G.; Ches, L.; Axel, R.; Kappler, J.; Marrack, P. Functional Interaction Between Human T-Cell Protein CD4 and the Major Histocompatibility Complex HLA-DR Antigen. Nature 1987, 328, 626-629.

10. Wu, L.; Gerard, N. P.; Wyatt, R.; Choe, H.; Parolin, C.; Ruffing, N.; Borsetti, A.; Cardoso, A. A.; Desjardin, E.; Newman, W.; Gerard, C.; Sodroski, J. CD4-Induced Interaction of Primary HIV-1 gp120 Glycoproteins with the Chemokine Receptor CCR-5. Nature 1996, 384, 179-183.

11. Lapham, C. K.; Ouyang, J.; Chandrasekhar, B.; Nguyen, N. Y.; Dimitrov, D. S.; Golding, H. Evidence for Cell-Surface Associations Between Fusin and the CD4-gp120 Complex in Human Cell Lines. Science 1996, 274, 602-605.

12. Veillette, A.; Bookman, M. A.; Horak, E. M.; Bolen, J. B. The CD4 and CD8 T Cell Surface Antigens are Associated with the Internal Membrane Tyrosine-Protein Kinase p56lck. Cell 1988, 55, 301-308.

13. Sheng, M.; Cummings, J.; Roldan, L. A.; Jan, Y. N.; Jan, L. Y. Changing Subunit Composition of Heteromeric NMDA Receptors During Development of Rat Cortex. Nature 1994, 368, 144-147.

14. Lynch, G. W.; Sloane, A. J.; Raso, V.; Lai, A.; Cunningham, A. L. Direct Evidence for Native CD4 Oligomers in Lymphoid and Monocytoid Cells. Eur. J. Immunol. 1999, 29, $2590-2602$.

15. Loo, J. A.; Ogorzalek-Loo, R. R. Applying Charge Discrimination with Electrospray Ionisation-Mass Spectrometry to Protein Analyses. J. Am. Soc. Mass Spectrom. 1995, 6, 1098 1104.

16. Cruikshank, W. W.; Center, D. M.; Nisar, N.; Wu, M.; Natke, B.; Theodore, A. C.; Kornfeld, H. Molecular and Functional Analysis of a Lymphocyte Chemoattractant Factor: Association of Biologic Function with CD4 Expression. Proc. Natl. Acad. Sci. U.S.A. 1994, 91, 5109-5113. 
17. Moseley, A. M. Current Trends in Differential Expression Proteomics: Isotopically Coded Tags. Trends Biotech. 2001, 19, S10-S16.

18. Percherancier, Y.; Lagane, B.; Planchenault, T.; Staropoli, I.; Altmeyer, R.; Virelizier, J.-L.; Arenzana-Seisdedos, F.; Hoessli, D. C.; Bachelerie, F. HIV-1 Entry into T-cells Is Not Dependent on CD4 and CCR5 Localization to Sphingolipid-Enriched, Detergent-Resistant Raft Membrane Domains. J. Biol. Chem. 2003, 278, 3153-3161.

19. Husi, H.; Grant, S. G. N. Isolation of 2000-kDa Complexes of $\mathrm{N}$-Methyl-D-Aspartate Receptor and Postsynaptic Density 95 from Mouse Brain. J. Neurochem. 2001, 77, 281-291.

20. Tingley, W. G.; Roche, K. W.; Thompson, A. K.; Huganir, R. L. Regulation of NMDA Receptor Phosphorylation by
Alternative Splicing of the C-Terminal Domain. Nature 1993, 364, 70-73.

21. Knuesel, M. P., Wan, Y., Xiao, Z., Holinger, E. P., Lowe, N., Wang, W., Liu, X. Identification of Novel Protein-Portein Interactions Using a Versatile Mammalian TAP Expression System. Mol. Cell. Proteomics, unpublished. [Epub ahead of print].

22. Thuillier, L.; Hivroz, C.; Fagard, R.; Andreaoli, C.; Mangeat, P. Ligation of CD4 Surface Antigen Induces Rapid Tyrosine Phosphorylation of the Cytoskeletal Proten Ezrin. Cell. Immunol. 1994, 156, 322-331.

23. Kinch, M. S.; Sanfridson, A.; Doyle, C. The Protein Tyrosine Kinase p561ck Regulates Cell Adhesion Mediated by CD4 and Major Histocompatibility Complex Class II Proteins. J. Exp. Med. 1994, 180, 1729-1739. 